\title{
Bartter's Syndrome: A Rare Cause of a Severe Metabolic Abnormality in a Pre-term Neonate
}

\author{
Maj B Moorthy \\ MD, MRCP, RAMC \\ Consultant Paediatrician \\ Maj S J Cade \\ MRCGP, RAMC \\ SHO in Paediatrics \\ Cambridge Military Hospital Aldershot
}

SUMMARY: A premature neonate with a severe form of Bartter's Syndrome is presented. Clinical features, diagnosis, treatment and prognosis of Bartter's Syndrome are discussed.

\section{Case Report}

The male infant was born to unrelated parents, after 35 weeks of uneventful pregnancy, by normal delivery with a birth weight of $2.302 \mathrm{kgs}$ (10th percentile). The mother was noted to have minimally increased liquor on routine antenatal scanning. The baby had minimal birth asphyxia needing oxygen by bag and mask for 2 minutes, but the cord blood gas showed a $\mathrm{pH} 7.05$ with a negative base excess of $17.7 \mathrm{mmol} / 1$. He was initially observed in the special care baby unit (SCBU) for 2 days, and was transferred to the mother on day 3 . He had mild jaundice (max bilirubin $250 \mathrm{mmol} / 1$ on day 5 ) and needed phototherapy for 24 hours. He was transferred to SCBU on the 10th day in a collapsed condition, hypothermic $\left(35^{\circ} \mathrm{C}\right)$, with a poor respiratory effort. He had lost $165 \mathrm{gms}$ from his birth weight of $2.302 \mathrm{gms}(7.2 \%)$. He was ventilated, because of poor respiratory effort and an infection screen, including a lumbar puncture, was performed. He was started on penicillin, gentamycin and flucloxacillin. He remained normotensive (BP $70 / 40 \mathrm{mmHg}$ ). He was found to be hyponatraemic (sodium $97 \mathrm{mmol} / 1$ ), hypokalaemic (potassium $1.1 \mathrm{mmol} / 1$ ), hypocalcaemic (calcium $1.9 \mathrm{mmol} / 1$ ) and hypochloraemic (chloride $19 \mathrm{mmol} / 1$ ). He had normal renal function (urea $1.2 \mathrm{mmol} / 1$, creatinine $33 \mathrm{mmol} / 1$ ) and was noted to be in metabolic alkalosis $\left(\mathrm{pH} 7.65, \mathrm{PCO}_{2} 5.6 \mathrm{KPA}, \mathrm{HCO} 347 \mathrm{mmol} / 1\right.$ and base excess of $+22.4 \mathrm{mmol} / 1$ ). His electrolyte abnormalities were conservatively managed with slow intravenous infusion of $10 \%$ dextrose and additives, appropriately calculated for correction with $30 \%$ sodium chloride, $20 \%$ potassium chloride and $10 \%$ calcium gluconate, over a period of 72 hours, by which time the electrolytes gradually improved $\left(\mathrm{Na}+122 \mathrm{mmol} / 1, \mathrm{~K}^{+}\right.$ $\left.2.2 \mathrm{mmol} / 1, \mathrm{Ca}^{++} 2.2 \mathrm{mmol} / 1, \mathrm{Cl}^{-} 79 \mathrm{mmol} / \mathrm{l}\right)$ but he continued to have metabolic alkalosis $\left(\mathrm{pH} 7.51, \mathrm{PCO}_{2}\right.$ $7.1 \mathrm{KPA}, \mathrm{HCO}_{3} 42 \mathrm{mmol} / 1$, base excess $\left.+17 \mathrm{mmol} / 1\right)$.

He had many generalised seizures for which he was given intravenous phenobarbitone $(20 \mathrm{mg} / \mathrm{kg})$ and paraldehyde. Ultrasound of the brain showed evidence of bilateral subependymal haemorrhages and cerebral oedema. He was continued on oral phenobarbitone but the antibiotics were discontinued after a period of 72 hours, because of negative blood and CSF cultures. He was extubated after 72 hours and was started on nasogastric feeds which he tolerated well. He was transferred to the Nephrology department at the Hospital for Sick Children, Great Ormond Street, London, for further management, with a presumptive diagnosis of Bartter's Syndrome.

At the Hospital for Sick Children, he was found to beo normotensive, with normal renal function. $\mathrm{He}$ was hypochloraemic, hypokalaemic and in metabolic alka losis. His ultrasound scan of kidneys and brain wer normal. Two dimensional echo cardiogram showed possible patent duct arteriosus (PDA) even though the systolic murmur could be heard only intermittently. The diagnosis of Bartter's Syndrome was confirmed b increased plasma renin activity (PRAS (18000ng/AI/L/HR-normal range 472-3130) and raised blood cell intra-cellular sodium $(19 \mathrm{mmol} / 1$-normal range upto $4 \mathrm{mmol} / 1)$. He was started on indomethacin at $1 \mathrm{mg} / \mathrm{kg} /$ day along with sodium and potassium supplements and the dose of indomethacin was adjusted depending on his blood and urinary electrolytes and also on red cell sodium and plasma renin activity. Phenobarbitone was gradually reduced and stopped by 6 months of age. He is getting regular physiotherapy to improve his muscle strength. He continues to remain well but is still on indomethacin $(2.2 \mathrm{mg} / \mathrm{kg} /$ day $)$, potassium ( $60 \mathrm{mmol} /$ day) and sodium ( $20 \mathrm{mmol} /$ day) supplements. He is 17 months old with a corrected age of 15 $3 / 4$ months. His developmental age is around 11 months, which gives a development quotient of $70 \%$. $\mathrm{He}$ continues to thrive poorly, his weight, height and head circumference are just below the 3 rd centile, but he remains a happy, content infant. His blood pressure remains normal and he has normal renal function.

$\mathrm{He}$ is one of the youngest patients to ever have an established diagnosis of Bartter's Syndrome. With indomethacin therapy and adequate sodium and potassium supplements he should continue to maintain satisfactory renal function and remain normotensive, and at the same time grow and develop satisfactorily. 


\section{Discussion}

In 1962, Bartter et al described a clinical syndrome of growth and developmental retardation with hypokalaemic metabolic alkalosis and hyperreninaemic hyperaldosteronism (1). These patients also have many other renal tubular dysfunctions, presenting as rickets, renal failure and dehydration (2).

The majority of children with Bartter's Syndrome present by the age of two with symptoms of failure to thrive, vomiting and constipation, most of them presenting in the latter half of the first year (3). Distinctive facial appearance with prominent forehead, triangular facies, drooping mouth, large eyes and large pinnae have been observed (4). Symptoms of volume depletion, polyuria, polydypsia and fatigue seen in children with Bartter's Syndrome are due to renal tubular dysfunction and subsequent hypokalaemia and the majority of these patients are normotensive (2). Rarely polyhydramnios has been observed antenatally and should raise the suspicion of Bartter's Syndrome which can be diagnosed antenatally by biochemical examination of the amniotic fluid $(3,5)$.

The classical biochemical abnormalities of Bartter's Syndrome are hypokalaemic metabolic alkalosis, increased (PRA) and elevated aldosterone levels (1). Abnormal renal tubular function with increased urinary losses of sodium, potassium chloride and calcium are very common $(6,7)$. In addition, these patients also have impaired tubular acidification mimicking distal renal tubular acidosis (8). Abnormal intracellular concentration of sodium in the red cells and muscle cells, observed in these patients, are often considered diagnostic of Bartter's Syndrome $(9,10)$. Hypercalcaemia, hypophosphataemia and hypomagnesmia are often noted in Bartter's Syndrome $(3,11)$. Hypercalciuria leading to nephrocalcinosis and progressive renal failure and rickets have been rarely seen in these patients $(3,12)$.

Fanconi Syndrome, incomplete renal tubular acidosis, (RTA), cystic fibrosis, Conn's Syndrome, cyclical vomiting and Gitelman's Syndrome may have clinical and biochemical parameters, similar to Bartter's Syndrome (2). Fanconi Syndrome characteristically has glycosuria and aminoaciduria and distal RTA has hyperchloraemic acidosis $(8,13)$. Cyclical vomiting and cystic fibrosis can be distinguished clinically but these patients have a lower urine chloride compared to children with Bartter's Syndrome, even though the blood biochemical parameters may be similar, presenting as pseudo-Bartter's Syndrome $(14,15)$. Patients with Conn's Syndrome or primary hyperaldosteronism usually are hypertensive and may have biochemical parameters similar to Bartter's Syndrome (16). Gitelman's Syndrome, which has characteristic magnesiuria, is usually difficult to distinguish from Bartter's Syndrome, but these patients, usually are hypocalcaemic and have elevated PRA and aldosterone levels, but these values normally are lower than in Bartter's Syndrome (17).

Indomethacin, a prostaglandin sythetase inhibitor,, has transformed the clinical management of Bartter's Syndrome by improving the biochemical abnormalities; the growth and development $(18,19)$. Indomethacin? appears to act by redistributing renal blood flow and by $\overrightarrow{\vec{s}}$ improving proximal renal tubular reabsorption (2). It is usually given in a daily dose of $2-5 \mathrm{mgs} / \mathrm{kg}$ body weight in 4-6 divided doses and has few side effects (2). Infrequently patients develop gastrointestinal intoler-专 ance and impairment of renal function, which are usually improved by reducing the dose, or rarely by discon-o tinuing the drug for a short time (2). In addition to $\overrightarrow{0}$ indomethacin, these patients also will need sodium and potassium supplements to maintain a normal or near normal biochemical profile $(2,3)$.

Since the introduction of indomethacin in the treat-㧛 ment of Bartter's Syndrome, the wellbeing of these? children has improved remarkably and they remain in $a \vec{\infty}$ better electrolyte balance, but the improvement neurodevelopment may not be as striking as in physical growth and biochemical parameters (2). Occasionally $\vec{s}$ some of these children develop chronic renal failure secondary to nephrocalcinosis (3). It is usually advisedthat children with Bartter's Syndrome should remain 81 tr treatment with indomethacin and electrolyte suppere-? ments till the growth is complete whereas asymp tomatic adults of normal height will not require tre ment (2).

\section{REFERENCES}

1. Bartter F C, Pronove P, Gill J R, MacCradle R. Diller. E. Hyperplasia of the juxta glomerular complex with hyperaldosteronism and hypokalaemic alkalosis new syndrome. Am J Med 1962;33;811-28.

2. Dillon M J. Disorders of renal tubular handling of sodium and potassium. Textbook of Paediatric Nephrology - Holliday \& Barrett. Published by Williams and Wilkins 1987 2nd Edition Ch33 598-601.

3. Dillon M J, Shah V, Mitchell M D. Bartter's Syndrome - 10 cases in childhood. Results of long term indomethacin therapy. $Q J \mathrm{Med}$ 1976;48:429.

4. James T Holland N H, Preston D. Bartter's Syndrome Typical facies and normal plasma volume. Am J Dis Child 1975;129:1205.

5. Proesmans W, Massa G, Vanden Berghe $\mathrm{K}$, Va安 Assche A. Prenatal diagnosis of Bartter's Syndrome Lancet $1987 ; 1: 394$.

6. White M G. Bartter's Syndrome. A manifestation of renag tubular defects. Arch Intern Med 1975;129;41.

7. BartTer F C, DELEN C S, Kawasaki T. The adrenal coro tex and the kidney. Kidney Int 1974; 6:272.

8. Rodriguez Soriano J, Vallo A, Oliveros R. Bartter' $\$$ Syndrome presenting with features resembling renal tubuㅡㅡ. lar acidosis. Improvement of renal tubular defects by indomethacin. Hch Paed Acta 1978; 33:141.

9. Oliver J F, Delaney V B, Bourke E. Increased erythro cyte sodium permeability in patients with Bartter' Syndrome. Miner Electrolyte Metab 1978; 1:225. 
10. Gardner J D, Simopoulis A P, Lapey A. Altered membrane sodium transport in Bartter's Syndrome. J Clin Invest $1972 ; \mathbf{5 1 : 1 5 6 5}$.

11. Mace J W, Hambidge K M, Gotlin R W. Magnesium supplementation in Bartter's Syndrome. Arch Dis Child 1973; 48:485.

12. McCredie D A, Rotenburg E, Williams A L. Hypercalciuria in potassium losing nephropathy - a variant of Bartter's Syndrome. Aust Paediatr J 1974; 10: 286.

13. Takeda R, Mortimoto S, Kuroda M. Renal tubular acidosis presenting as a syndrome resembling Bartter's Syndrome in a patient with arachanodactyly. Acta Endocrinol 1973; 73:531.

14. Gotlieb R P. Metabolic alkalosis in cystic fibrosis. $J$ Pediatr 1971; 79:930.

15. Kennedy J D, Dinwiddie R, Daman-Willems C, Dillon
M J, MATHEw D J. Pseudo Bartter's Syndrome in cystic fibrosis. Arch Dis Child 1990;65:786-7.

16. Schambelan M, Slaton P E, Biglieri E G. Mineralocorticoid production in hyperadrenocorticism; role in pathogenesis of hypokalaemic alkalosis. Am J Med 1971; 51:299.

17. Gitelman H J, Graham J B, Welt L G. A new familial disorder characterised by hypokalaemia and hypomagnesimia. Trans Assoc Am Physicians 1966; 79:221.

18. Verberckmoes R, Van Damme B, Clement J. Bartter's Syndrome with hyperplasia of reno medullary cells: successful treatment with indomethacin. Kidney Int 1976; 9:302.

19. Winterborn M H, Hewitt G J, Mitchell M. Role of prostaglandins in Bartter's Syndrome. Int $J$ Pediatr Nephrol 1984; 5:1 31-38. 